\title{
Forecasting Real U.S. House Prices: Principal Components Versus Bayesian Regressions
}

Rangan Gupta, University of Pretoria, South Africa Alain Kabundi, University of Johannesburg, South Africa

\begin{abstract}
This paper analyzes the ability of principal component regressions and Bayesian regression methods under Gaussian and double-exponential prior in forecasting the real house prices of the United States (U.S.), based on a monthly dataset of 112 macroeconomic variables. Using an insample period of 1992:01 to 2000:12, Bayesian regressions are used to forecast real U.S. house prices at the twelve-months-ahead forecast horizon over the out-of-sample period of 2001:01 to 2004:10. In terms of the Mean Square Forecast Errors (MSFEs), our results indicate that a principal component regression with only one factor is best-suited for forecasting the real U.S. house prices. Among the Bayesian models, the regression based on the double exponential prior outperforms the model with Gaussian assumptions.
\end{abstract}

Keywords: Bayesian Regressions; Principal Components; Large-Cross Sections

\section{INTRODUCTION}

$\mathscr{J}$ his paper analyzes the ability of Bayesian regression methods under Gaussian and double-exponential prior in forecasting the real house price of the United States (US), based on a monthly dataset of 112 macroeconomic variables. Using an in-sample period of 1992:01 to 2000:12, Bayesian regressions are used to forecast real U.S. house prices at the twelve-months-ahead forecast horizon over the out-of-sample period of 2001:01 to 2004:10. The forecast performance of the Bayesian regressions are then compared in terms of the Mean Square Forecast Errors (MSFEs) with the forecasts generated from the principal component regression, based on the same dataset of 112 variables. Our choice of the two Bayesian priors is motivated by the recent contribution by De Mol et al. (2008) and corresponds to the two interesting cases of variable aggregation and variable selection. ${ }^{1}$

With the methodologies in place, two questions arise immediately. First, why is forecasting real house price important? And second, why use large-scale models for this purpose? As far as the answer to the first question is concerned, the importance of predicting house price is motivated by a set of recent studies which conclude that asset prices help forecast both inflation and output (Forni et al., 2003; Stock and Watson, 2003, Gupta and Das, 2008a,b and Das et al., 2008a,b). Since a large amount of individual wealth is imbedded in houses, similar to other asset prices, house price movements are thus important in signaling inflation. Models that forecast real house price can give policy makers an idea about the direction of overall price level and, hence, economy-wide inflation in the future, and thus, can provide a better control for designing of appropriate policies. In addition, given that movements in the housing market are likely to play an important role in the business cycle (Iacoviello and Neri, 2008), not only because housing investment is a very volatile component of demand (Bernanke and Gertler, 1995), but also because changes in house prices tend to have important wealth effects on consumption (International Monetary Fund, 2000) and investment (Topel and Rosen, 1988), and hence, the importance of forecasting house price is vital. The housing sector thus plays a significant role in acting as a leading indicator of the real sector of the economy and predicting it correctly cannot be overemphasized, especially in the light of the recent credit crunch in the U.S. that started with

\footnotetext{
${ }^{1}$ See The Models section for further details.
} 
the burst of the housing price bubble which, in turn, transmitted to the real sector of the economy driving it towards an imminent recession.

The rationale for using large-scale models to forecast real house price emanates from the fact that a large number of economic variables help in predicting real housing price (Cho, 1996; Abraham and Hendershott, 1996; Johnes and Hyclak, 1999; and Rapach and Strauss, 2007, 2008). For instance, income, interest rates, construction costs, labor market variables, stock prices, industrial production, consumer confidence index - which are amongst the 112 monthly series used by the models - all act as potential predictors.

To realize the contribution of this study, it is important to place this paper in the context of current research that focuses on forecasting in the housing market. In this regard, few studies are worth mentioning: Rapach and Strauss (2007) used an autoregressive distributed lag (ARDL) model framework, containing 25 determinants, to forecast real housing price growth for the individual states of the Federal Reserve's Eighth District. Given the difficulty in determining apriori particular variables that are most important for forecasting real housing price growth, the authors also use various methods to combine the individual ARDL model forecasts, which result in a better forecast of real housing price growth. Rapach and Strauss (2008) do the same for the 20 largest U.S. states based on ARDL models containing a large number of potential predictors, including state, regional and national level variables. Once again, the authors reach similar conclusions as far as the importance of combining forecasts are concerned. On the other hand, Gupta and Das (2008b), look into forecasting the recent downturn in real house price growth rates for the 20 largest states in the U.S. In this paper, the authors use Spatial Bayesian VARs (BVARs), ${ }^{2}$ based merely on real house price growth rates, to predict their downturn for the period of 2007:01 to 2008:01. They find that, though the models are quite well-equipped in predicting the recent downturn, they underestimate the decline in the real house price growth rates by quite a margin. They attribute this underprediction of the models to the lack of any information on fundamentals in the estimation process.

Given that in practice, forecasters and policymakers often use information from many series than the ones included in smaller models, like the ones used by Rapach and Strauss $(2007,2008)$ who also indicate the importance of combining forecasts from alternative models, the role of a large-scale models cannot be ignored. In addition, one cannot condone the fact that the main problem of small models, as seen from the studies by Rapach and Strauss $(2007,2008)$, is in the decision regarding the choice of the correct potential predictors to be included. Due to this reason, Vargas-Silva (2008) and Gupta and Kabundi (2009a,b) use Factor Augmented Vector Autoregression (FAVAR) models containing a large number of macroeconomic variables in analyzing the impact of monetary policy shocks on the housing sector of the United States and South Africa. To the best of our knowledge, this is the first attempt to look into the ability of Bayesian and principal component regressions in forecasting real house prices in the U.S.

In such a backdrop, our paper can thus be viewed as an extension of the above-mentioned studies, in the sense that we use large-scale models that allow for the role of a wide possible set of fundamentals to affect the housing sector. The remainder of the paper is organized as follows: Section 2 lays out the basics of the alternative models. In Section 3, we discuss the data and evaluate the forecasting performances of the various models; and finally, Section 5 concludes.

\section{THE MODELS ${ }^{3}$}

Consider the $(n \times 1)$ vector of covariance-stationary processes $Z_{t}=\left(z_{1 t}, \ldots, z_{n t}\right)^{\prime}$. It will be assumed that they all have a mean of zero and a variance of unity. We are interested in forecasting linear transformations of some element(s) of $Z_{t}$ based on all the variables as possible predictors. Formally, we are interested in estimating the linear

\footnotetext{
${ }^{2}$ Prior to this study, the use of BVARs in the housing market can be found in Dua and Smyth (1995), Dua and Miller (1996) and Dua et al. (1999). These studies used coincident and leading indexes in BVAR models to forecast home sales for the state of Connecticut and the overall US economy, respectively.

${ }^{3}$ This section relies heavily on the discussion available in De Mol et al. (2008), and, also retains their symbolic representations.
} 
projection:

$y_{t+b / t}=\operatorname{proj}\left\{y_{t+b} / \Omega_{t}\right\}$

where $\Omega_{t}=\operatorname{span}\left\{Z_{t-p}, p=0,1,2, \ldots\right\}$ is a potentially large time $t$ information set and $y_{t+b}=z_{i, t+b}^{b}=f_{b}(L) z_{i, t+b}$ is a filtered version of $z_{i t}$, for a specific $i$.

Traditionally, time series models approximate the projection using only a finite number, $p$, of lags of $Z_{t}$. In particular, we generally consider the following regression:

$y_{t+b}=Z_{t}^{\prime} \beta_{0}+\ldots+Z_{t-p}^{\prime} \beta_{p}+u_{t+b}=X_{t}^{\prime} \beta+u_{t+b}$

where $\beta=\left(\beta_{0}^{\prime}, \ldots, \beta_{p}^{\prime}\right)$ and $X_{t}=\left(Z_{t}^{\prime}, \ldots, Z_{t-p}^{\prime}\right)^{\prime}$.

Given a sample of size of $T$, we will denote by $X=\left(X_{p+1}, \ldots, X_{T-b}\right)^{\prime}$ the $(T-b-p) \times n(p+1)$ matrix of observations for the predictors and by $y=\left(y_{p+1+b, \ldots,}, y_{T}\right)^{\prime}$ the $(T-h-p) \times 1$ matrix of the observations on the dependent variable. The regression coefficients are generally estimated by Ordinary Least Squares (OLS), $\hat{\beta}^{L S}=\left(X^{\prime} X\right)^{-1} X^{\prime} y$, and the forecast is given by $\hat{y}_{T+b / T}^{L S}=X_{T}^{\prime} \hat{\beta}^{L S}$. Naturally, when the size of the information set, $n$, is large, such projection involves the estimation of a large number of parameters. This leads to loss of degrees of freedom and large out-of-sample forecast errors. Besides, OLS is not feasible when the number of regressors is larger than the sample size, i.e., $n(p+1)>T$. To solve this problem of curse of dimensionality, the method that has been considered in the literature is to compute the forecast as a projection on the first few principal components (Stock and Watson, 2002a, b; Forni et al., 2005; Giannone et al. 2004).

Consider the spectral decomposition of the sample covariance matrix of the regressors:

$S_{x} V=V D$

where $D=\operatorname{diag}\left(d_{1}, \ldots, d_{n(p+1)}\right)$ is a diagonal matrix, with the diagonal elements constituted of the eigenvalues of $S_{x}=\frac{1}{T-b-p} X^{\prime} X$ in decreasing order of magnitude and $V=\left(v_{1}, \ldots, v_{n(p+1)}\right)$ is the $n(p+1) \times n(p+1)$ matrix whose columns are the corresponding eigenvectors ${ }^{4}$. Given this, the normalized principal components (PC) are defined as:

$\hat{f}_{i t}=\frac{1}{\sqrt{d_{i}}} v_{i}^{\prime} X_{t}$

${ }^{4}$ The eigenvalues and eigenvectors are typically computed on $\frac{1}{T-p} \sum_{t=p+1}^{T} X_{t} X_{t}^{\prime}$ (see Stock and Watson, 2002a). We follow De Mol et al. (2008) in computing them on $\frac{1}{T-b-p} X^{\prime} X=\frac{1}{T-p-b} \sum_{t=p+1}^{T-b} X_{t} X_{t}^{\prime}$ for comparability with other estimators considered in the paper. 
for $i=1, \ldots, N$, where $N$ is the number of non zero eigenvalues ${ }^{5}$.

If there is limited cross-correlation among the specific components of the data and if most of the interactions amongst the variables in the information set emerge due to few common factors, the information contained in the large date set can be captured by few aggregates, while the part not explained by the common factors can be predicted by means of traditional forecasting methods. In such instances, few principal components, $\hat{F}_{t}=\left(\hat{f}_{1 t}, \ldots, \hat{f}_{1 t}\right)$ with $r \square n(p+1)$, are likely to provide a good approximation of the underlying factors.

Assuming, for the sake of simplicity, that no lags of the dependent variable are required as additional regressors, the principal component forecast is defined as:

$$
y_{t+b / t}^{P C}=\operatorname{proj}\left\{y_{t+b} / \Omega_{t}^{F}\right\} \approx \operatorname{proj}\left\{y_{t+b} / \Omega_{t}\right\}
$$

where $\Omega_{t}^{F}=\operatorname{span}\left\{\hat{F}_{t}, \hat{F}_{t-1}, \ldots,\right\}$ is a parsimonious representation of the information set. Given the parsimonious approximation, the projection is now feasible since it requires the estimation of a limited number of parameters. Under assumptions defining an approximate factor structure, ${ }^{6}$ once common factors have been estimated via principal components, the projection is computed by OLS by treating the estimated factors as observable variables.

On the other hand, the Bayesian approach imposes limits on the length of $\beta$ through priors and estimates the parameters as the posterior mode. Hence, here the parameters are used to compute the forecasts. As in De Mol et al. (2008), we also consider two alternative prior specifications; namely, Gaussian and double exponential priors.

Under the Gaussian prior, $u_{t} \square$ i.i.d. $N\left(0, \sigma_{u}^{2}\right)$ and $\beta \square N\left(\beta_{0}, \Phi_{0}\right)$, and assuming for simplicity, that $\beta_{0}=0$, we have:

$\hat{\beta}^{b a y}=\left(X^{\prime} X+\sigma_{u}^{2} \Phi_{0}^{-1}\right)^{-1} X^{\prime} y$

The forecast then is computed as:

$$
\hat{y}_{T+b / T}^{b a y}=X_{T}^{\prime} \hat{\beta}^{b a y}
$$

When the parameters are independently and identically distributed, i.e., $\Phi_{0}=\sigma_{\beta}^{2} I$, the estimates are

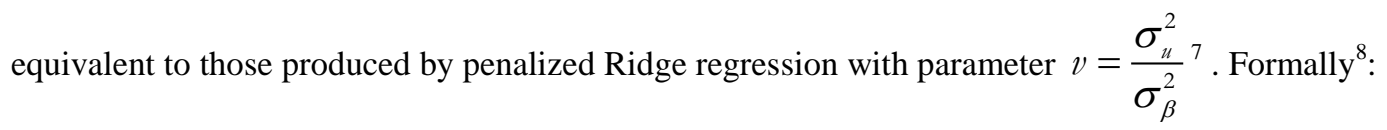

\footnotetext{
${ }^{5}$ Note that $N \leq \min \{n(p+1), T-b-p\}$.

${ }^{6}$ See Section 3 for further details.

${ }^{7}$ Though, homogenous variance and zero mean are too simplistic of assumptions, they are justified by the fact that the variables in the panel are standardized and demeaned. Note, this transformation is obvious to allow for comparison with principal components.

${ }^{8}\|$.$\| denotes the L^{2}$ matrix norm, i.e. for every matrix $\mathrm{A},\|A\|=\sqrt{\lambda \max \left(A^{\prime} A\right)}$. For vectors it corresponds to the Euclidean norm.
} 


$$
\hat{\beta}^{\text {bay }}=\arg \min _{\beta}\left\{\|y-X \beta\|^{2}+v\|\beta\|^{2}\right\} .
$$

OLS, principal components regression, and Gaussian Bayesian regression tend to weight all the variables. ${ }^{9}$ An alternative to this is to select variables. Under Bayesian regression, one can use a double exponential prior to do so, which, when useing a zero mean i.i.d. prior, is equivalent to Lasso regression (least absolute shrinkage and selection operator). In this particular case, the method can also be seen as a penalized regression with a penalty on the coefficients involving the $L_{1}$ norm instead of the $L_{2}$ norm. Specifically:

$$
\hat{\beta}^{\text {lasso }}=\arg \min _{\beta}\left\{\|y-X \beta\|^{2}+v \sum_{i=1}^{n}\left|\beta_{i}\right|\right\}
$$

where $v=\frac{1}{\tau}$ where $\tau$ is the scale parameter of the prior density ${ }^{10}$.

In comparison with the Gaussian density, the double-exponential puts more mass near zero and in the tails which, in turn, tends to produce coefficient estimates that are either large or zero. As a result, one often favors the recovery of a few large coefficients instead of many fairly small ones. Moreover, the double-exponential prior favors sparse regression coefficients (sparse mode) since it favors truly zero values instead of small ones.

In the case with non-orthogonal regressors, the Lasso solution enforces sparsity on the variables rather than on the principal components, which implies a regression on few observables rather than on few linear combinations of the variables. Unfortunately, in the general case, the maximizer of the posterior distribution has no analytical form and has to be computed based on numerical methods. Following De Mol et al. (2008), we use the Least Angle Regression (LARS) algorithm developed recently by Efron et al. (2004) for this purpose.

The next section will consider the empirical performance of the three methods discussed in an out-ofsample forecast exercise based on a large panel of time series.

\section{DATA AND RESULTS}

The data set employed for the out-of-sample forecasting analysis is the same as the 111 major macroeconomic variables used by Boivin et al. (2008). With this data set ending at 2005:10, the endpoint of our sample is automatically determined. The data set contains a broad range of macroeconomic variables, such as industrial production, income, employment and unemployment, housing starts, inventories and orders, stock prices, exchange rates, interest rates, money aggregates, consumer prices, producer prices, earnings, and consumption expenditure. As far as the U.S. house prices are concerned, the nominal house price figures were obtained from the Office of Federal Housing Enterprise Oversight (OFEO) and were converted to their real counterpart by dividing them with the personal consumption expenditure deflator. So, in total, we have a balanced panel of 112 monthly series for the period running from 1991:01 to 2005:10. A full description of the dataset has been provided in Tables $\mathrm{A} 1$ and $\mathrm{A} 2$ in the appendix of the paper.

Series are transformed to induce stationarity. In general, following, De Mol et al. (2008), all real variables, such as employment, industrial production, sales and the real U.S. house prices, we take monthly growth rate. While for series that are already expressed in rates, such as the unemployment rate, capacity utilization, interest rate and some surveys, we take first differences. Finally, from nominal prices and wages, we take the first differences of their annual rates.

Defining $H P$ as the monthly real U.S. house price, the relevant variable that we forecast is:

\footnotetext{
${ }^{9}$ See De Mol et al. (2008) for further details.

${ }^{10}$ Recall that the variance of the prior density is proportional to $2 \tau^{2}$.
} 


$$
\mathrm{z}_{\mathrm{HP}, \mathrm{t}+\mathrm{h}}^{\mathrm{h}}=\left(\mathrm{hp}_{\mathrm{t}+\mathrm{h}}-\mathrm{hp}_{\mathrm{t}}\right)=\mathrm{z}_{\mathrm{HP}, \mathrm{t}+\mathrm{h}}+\ldots \ldots . . \mathrm{z}_{\mathrm{HP}, \mathrm{t}+1} \text {, where } \mathrm{hp}_{\mathrm{t}}=100 \times \log \left(\mathrm{HP}_{\mathrm{t}}\right) \text {. The forecasts for the } \log (H P) \text { is }
$$

then recovered as: $h \mathrm{P}_{\mathrm{T}+\mathrm{h} \mid \mathrm{T}}^{\mathrm{F}}=\mathrm{z}_{\mathrm{HP}, \mathrm{T}+\mathrm{h} \mid \mathrm{T}}^{\mathrm{h}}+h \mathrm{~h}_{\mathrm{T}}$. The accuracy of the forecasts is evaluated using the mean-square forecast error (MSFE), given by: $\mathrm{MSFE}_{\mathrm{hp}}^{\mathrm{h}}=\frac{1}{\mathrm{~T}_{1}-\mathrm{T}_{0}-\mathrm{h}+1} \sum_{\mathrm{T}=\mathrm{T}_{0}}^{\mathrm{T}_{\mathrm{i}}-\mathrm{h}}\left(\mathrm{h} \mathrm{p}_{\mathrm{T}+\mathrm{h} \mid \mathrm{T}}^{\mathrm{F}}-\mathrm{hp} \mathrm{p}_{\mathrm{T}+\mathrm{h}}\right)^{2}$.

The sample has a monthly frequency range from 1991:01 to 2005:10, with the starting point of the sample determined by the availability of monthly U.S. house prices. The out-of-sample period is 2001:01 to 2004:10 with data between 1992:01 and 2000:12 serving as the in-sample for the analysis; i.e., $T_{0}=2000: 12$. The last available time point is $T_{1}=2005: 10$. We consider rolling estimates with a window of nine years. In other words, parameters are estimated at each time $T$ using the most recent nine years of data. ${ }^{11}$. All the procedures have been applied to standardized data, and, hence, mean and variance have been re-attributed to the forecasts accordingly. Following De Mol et al. (2008), the results for $h=12$, under the principal components regression and the Bayesian regressions under the Gaussian and double-exponential priors, have been reported in Tables 1 through 3, respectively. We compare across the three models and can draw the following conclusions based on the MSFE relative to the random walk and the variance of the forecasts relative to the variance of the actual data for real U.S. house prices:

1. Principal Component Regression: Let us start with the principal component regression where the results have been reported for the choice of $r=1,3,5,10,25,50$ and 75. Note when $r=0$, we have the random walk model with drift on the $\log$ of HP, while, when $r=n$, we have the OLS model. As in De Mol et al. (2008), we only report results for $p=0$, since this is the case for which the theory has been developed and is typically what is considered in standard macroeconomic applications. Results in Table 1 show principal components improve a lot over the random walk model, especially for $r=1$ and 10 , while for $\mathrm{r}=3$, it is nearly as good as the random walk model. But beyond $r=10$, the advantage is lost due to a possible loss in parsimony. Moreover, beyond $r$ equal to 10 and beyond, the variance of the forecasts becomes larger than the series itself. As pointed out by De Mol et al. (2008), this can be explained by the large uncertainty of the regression coefficients when we have a large number of explanatory aggregates. Overall, a principal component model with one regressor is best suited in forecasting real U.S. house prices relative to the random walk model, not only because it produces the minimum MSFE relative to the random walk model, but also because it results in lower variance for the forecasts relative to the original series.

2. Bayesian (Ridge) Regression with Gaussian Prior: For comparability with the principal component regression, we focus on the case $p=0$ also for the Bayesian regression, which implies that we do not consider any lags of the regressor. For the Bayesian regression under Gaussian prior, we run the regression using the first estimation period 1991 to 2000 for a grid of priors. Following De Mol et al. (2008), we then choose the priors that cause the in-sample fit to explain a given fraction $1-\kappa$ of the variance of the real U.S. house prices. We report the results for the different values of $\kappa$ and $v$, the latter kept fixed for the whole out-of-sample horizon. Note $\kappa=0$ corresponds to a case where the prior is quite uninformative and would be very close to the OLS model, while $\kappa=1$ implies the random walk case. Based on results reported in Table 2, the ridge regression performs better than the random walk model for all values of $\kappa$ beyond 0.1 , but especially well for values the same between 0.3 and 0.5 which, in turn, are associated with shrinkage parameters between three and ten times the cross-sectional dimension, $n$. However, the minimum MSFE of the Bayesian regression, under the Gaussian prior relative to the MSFE of the random walk model, is more than twice the minimum obtained under the principal component regression with $r=1$. However, the forecasts produced by the Ridge regressions are generally smoother than the principal component forecasts. Moreover, the principal component and the Ridge forecasts, as seen from the last line in Table 2, are highly correlated, though it is not the case that the correlation is maximal for priors giving the best forecasts, indicative of the fact that there does not exist a common explanation for the performance of the two methods.

\footnotetext{
${ }^{11}$ The choice of 9 years as the rolling-sample ensures that or out-of-sample horizon starts at 2001:01, but at the same time, this also allows us to use the maximum amount of data available for the in-sample analysis.
} 
3. Bayesian Regression with Double Exponential Prior: Finally, we consider the case of double-exponential priors. As in De Mol et $a$ l. (2008), instead of fixing the values of the parameter $\mathrm{U}$, a prior is selected that delivers a given number, say $k$, of non-zero coefficients at each estimation step in the out-of-sample period. We look at the cases of $\mathrm{k}=1,3,5,10,25,50$, and 75 non-zero coefficients. Results reported in Table 3 show that good forecasts relative to the random walk model are obtained with predictors between 1 to 5 , with the best being for the case of $k=3$, which is about 1.7 times more than the minimum obtained under the principal component regression. As far as correlation with principal component forecast is concerned for $k=3$, the value is second highest. Variance of the forecasts relative to the original data increases as the number of predictors increases, but it never exceeds the latter. Note that the four variables selected for $\mathrm{k} \approx 3$ at the beginning and at the end of the out-of-sample period have been reported in the last column of the Table A.2 describing the data in the appendix. Three of the four variables selected relate to the housing market; namely, housing starts in the northeast, total new private housing authorized and mobile homes, with the former two being picked up both at the beginning and end of the forecast evaluation period and the third one only appearing at the end of the out-of-sample horizon. The fourth variable; namely, the spread between the 10-year Treasury bonds yield and the Federal funds rate, is picked up at the beginning of the forecast evaluation period. Overall, these results tend to suggest the importance of the leading indicators related to the housing market, besides the long-term interest rate spread, as major determinants of the real U.S. house prices.

Table 1: Principal Component Forecasts

Real U.S. House Prices (2001:01-2004:10)

Number of Principal Components

\begin{tabular}{|l|c|c|c|c|c|c|c|}
\hline & 1 & 3 & 5 & 10 & 25 & 50 & 75 \\
\hline MSFE & $\mathbf{0 . 3 8 2}$ & 0.9927 & 1.1137 & 0.5024 & 1.2403 & 1.0304 & 1.2592 \\
\hline Variance* & 0.5323 & 0.5014 & 0.7336 & 1.0685 & 1.0865 & 1.0832 & 1.1328 \\
\hline
\end{tabular}

MSFE are relative to Random Walk forecast. *The variance of the forecast relative to the variance of the series.

Table 2: Bayesian Forecasts with Gaussian Prior

Real U.S. House Prices (2001:01-2004:10)

In-Sample Residual Variance

\begin{tabular}{|l|c|c|c|c|c|c|c|c|c|}
\hline & 0.1 & 0.2 & 0.3 & 0.4 & 0.5 & 0.6 & 0.7 & 0.8 & 0.9 \\
\hline $\mathbf{v}$ & 35 & 146 & 336 & 629 & 1066 & 1735 & 2855 & 5091 & 11790 \\
\hline MSFE (12-steps) & 1.0189 & 0.8348 & 0.7905 & $\mathbf{0 . 7 8 9 3}$ & 0.8072 & 0.8351 & 0.8692 & 0.9082 & 0.9517 \\
\hline Variance* & 0.6827 & 0.5823 & 0.5027 & 0.4468 & 0.4064 & 0.3755 & 0.3502 & 0.3282 & 0.3085 \\
\hline $\begin{array}{l}\text { Correlation with PC } \\
\text { forecasts (r=1) }\end{array}$ & 0.7284 & 0.8127 & 0.8614 & 0.8935 & 0.9147 & 0.9285 & 0.9374 & 0.9426 & 0.945 \\
\hline
\end{tabular}

MSFE are relative to Random Walk forecast. *The variance of the forecast relative to the variance of the series.

Table 3: Lasso Forecasts

Real U.S. House Prices (2001:01-2004:10)

Number of Non-Zero Coefficients

\begin{tabular}{|l|c|c|c|c|c|c|c|}
\hline & 1 & 3 & 5 & 10 & 25 & 50 & 75 \\
\hline MSFE(12-Steps) & 0.7367 & $\mathbf{0 . 6 5 5 7}$ & 0.8048 & 0.9316 & 1.1529 & 1.4734 & 1.748 \\
\hline Variance* & 0.4337 & 0.5981 & 0.6345 & 0.6838 & 0.7836 & 0.7894 & 0.6541 \\
\hline $\begin{array}{l}\text { Correlation with PC } \\
\text { forecasts (r=1) }\end{array}$ & 0.8932 & 0.8432 & 0.7842 & 0.7367 & 0.6745 & 0.6008 & 0.5552 \\
\hline
\end{tabular}

MSFE are relative to Random Walk forecast. *The variance of the forecast relative to the variance of the series. 


\section{CONCLUSIONS}

This paper analyzes the ability of principal component regressions and Bayesian regression methods under Gaussian and double-exponential prior in forecasting the real house prices in the United States (U.S.), based on a monthly dataset of 112 macroeconomic variables. Using an in-sample period of 1992:01 to 2000:12, the alternative regressions are used to forecast real U.S. house prices at the twelve-months-ahead forecast horizon over the out-ofsample period of 2001:01 to 2004:10. In summary, based on the 12-months-ahead forecast over the out-of-sample horizon of 2001:01 to 2004:10 and the MSFE relative to the random walk model, we can conclude that the principal component model with only one factor is best suited in forecasting the real U.S. house prices relative to the Bayesian regressions based on Gaussian and double-exponential priors. Within the two-types of Bayesian regressions, the Lasso forecasts with three non-zero coefficients tend to outperform the best-performing ridge-regression forecasts obtained under a shrinkage parameter of nearly six times the size of the cross-section.

Recent works by Banbura, et al. (2008) and Gupta and Kabundi (2008a,b) have indicated that large-scale Bayesian Vector Autoregressions (LBVARs) tend to outperform Factor-Augmented VARs (FAVARs) in forecasting key macroeconomic variables. In such a backdrop, future research would be aimed at analyzing the ability LBVARs in forecasting house prices.

\section{ACKNOWLEDGEMENT}

We are grateful to De Mol et al. (2008) for making the replication files available publicly. A special thanks to Domenico Giannone for many helpful comments regarding the implementation of the codes.

\section{AUTHOR INFORMATION}

Rangan Gupta is a Professor at University of Pretoria, Department of Economics, Pretoria, 0002, South Africa, Email: Rangan.Gupta@up.ac.za. Phone: +27 12420 3460, Fax: +27 123625207.

Alain Kabundi is an Associate Professor at University of Johannesburg, Department of Economics, Johannesburg, 2006, South Africa, Email: akabundi@uj.ac.za. Phone: +27 11559 2061, Fax: +27 115593039.

\section{REFERENCES}

1. Abraham, J.M., \& Hendershott, P.H. (1996). Bubbles in Metropolitan Housing Markets. Journal of Housing Research, 7(2), 191-207.

2. Bernanke, B., \& Gertler, M. (1995). Inside the Black Box: the Credit Channel of Monetary Transmission. Journal of Economic Perspectives, 9(4), 27-48.

3. Boivin, J., Giannoni, M., \& Mihov, I. (2008). Sticky Prices and Monetary Policy: Evidence from Disaggregated U.S. Data. Forthcoming American Economic Review.

4. Banbura, M., Giannone, D. \& Reichlin, L. (2008). Large Bayesian VARs. Forthcoming Journal of Applied Econometrics.

5. Cho, M. (1996). House Price Dynamics: A Survey of Theoretical and Empirical Issues. Journal of Housing Research, 7(2), 145-172.

6. Das, S., Gupta, R., \& Kabundi, A. (2008a). Is a DFM Well-Suited for Forecasting Regional House Price Inflation?" Working Paper No. 85, Economic Research Southern Africa.

7. Das, S., Gupta, R., \& Kabundi, A. (2008b). Could We Have Forecasted the Recent Downturn in the South African Housing Market? Working Paper No. 200831, Department of Economics, University of Pretoria.

8. De Mol, C., Giannone, D. \& Reichlin, L. (2008). Forecasting using a large number of predictors: Is Bayesian regression a valid alternative to principal components?, Journal of Econometrics, 146(2),318-328.

9. Dua, P. and Smyth, D. J. (1995). Forecasting U. S. Home Sales using BVAR Models and Survey Data on Households' Buying Attitude for Homes. Journal of Forecasting, 14(3), 217-227.

10. Dua, Pami, and Stephen M. Miller (1996), "Forecasting Connecticut Home Sales in a BVAR Framework Using Coincident and Leading Indexes”. Journal of Real Estate Finance and Economics 13: 219-235. 
11. Dua, P., Miller, S. M. and Smyth, D. J. (1999). Using Leading Indicators to Forecast U. S. Home Sales in a Bayesian Vector Autoregressive Framework. Journal of Real Estate Finance and Economics, 18(2), 191205.

12. Efron, B., Hastie, T., Johnstone, I., \& Tibshirani, R. (2004). Least angle regression. Annals of Statistics, 32(2), 407-499.

13. Forni, M., Hallin, M., Lippi, M., \& Reichlin, L. (2005). The Generalized Dynamic Factor Model, One Sided Estimation and Forecasting. Journal of the American Statistical Association, 100(471), 830-840.

14. Forni M., Hallin, M., Lippi, M., Reichlin, L. (2003). Do financial variables help forecasting inflation and real activity in the euro area? Journal of Monetary Economics,

15. Giannone, D., Reichlin, L., \& Sala, L. (2004). Monetary Policy in Real Time, in NBER Macroeconomics Annual, ed. by M. Gertler, and K. Rogoff, pp. 161-200. MIT Press.

16. Gupta, R., \& Das, S. (2008a). Spatial Bayesian Methods for Forecasting House Prices in Six Metropolitan Areas of South Africa. South African Journal of Economics, 76(2), 298-313.

17. Gupta, R., \& Das, S. (2008b). Predicting Downturns in the US Housing Market. Forthcoming Journal of Real Estate Economics and Finance.

18. Gupta, R., \& Kabundi, A. (2008a). Forecasting Macroeconomic Variables using Large Datasets: Dynamic Factor Model vs Large-Scale BVARs. Working Paper No. 200816, Department of Economics, University of Pretoria.

19. Gupta, R., \& Kabundi, A. (2008b). Forecasting Macroeconomic Variables in a Small Open Economy: A Comparison between Small- and Large-Scale Models. Working Paper No. 200830, Department of Economics, University of Pretoria.

20. Iacoviello, M., \& Neri, S. (2008). Housing Market Spillovers: Evidence from an Estimated DSGE Model. Working Paper No. 659, Boston College Department of Economics.

21. International Monetary Fund. World Economic Outlook: Asset Prices and the Business Cycle, 2000.

22. Johnes, G., \& Hyclak, T. (1999). House Prices and Regional Labor Markets. Annals of Regional Science, 33(1), 33-49.

23. Rapach, D.E., \& Strauss. J. K. (2008). Differences in Housing Price Forecast ability Across U.S. States. Forthcoming International Journal of Forecasting.

24. Rapach, D.E., \& Strauss, J.K. (2007). Forecasting Real Housing Price Growth in the Eighth District States. Federal Reserve Bank of St. Louis. Regional Economic Development, 3(2), 33-42.

25. Stock, J.H., \& Watson, M.W. (2003). Forecasting Output and Inflation: The Role of Asset Prices. Journal of Economic Literature, 41(3), 788-829.

26. Stock, J. H., \& Watson, M. W. (2002a). Forecasting Using Principal Components from a Large Number of Predictors," Journal of the American Statistical Association, 97, 147-162.

27. Stock, J.H., \& Watson, M.W. (2002b). Macroeconomic Forecasting Using Diffusion Indexes. Journal of Business and Economics Statistics, 20, 147-162.

28. Topel, R. H., \& Rosen, S. (1988). Housing Investment in the United States. Journal of Political Economy, 96(4), 718-740.

29. Vargas-Silva, C. (2008).The Effect of Monetary Policy on Housing: A Factor Augmented Approach. Applied Economics Letters, 15(10), 749-752. 


\section{APPENDIX}

\begin{tabular}{|l|l|l|}
\multicolumn{2}{|c|}{ Table A1: Data Transformation } \\
\hline 1 & DEFINITION & TRANSFORMATION \\
\hline 2 & $\mathrm{x}_{\mathrm{it}}=\mathrm{z}_{\mathrm{it}}$ & No transformation. \\
\hline 4 & $\mathrm{x}_{\mathrm{it}}=\Delta \mathrm{z}_{\mathrm{it}}$ & Monthly Difference \\
\hline 5 & $\mathrm{x}_{\mathrm{it}}=\ln \mathrm{z}_{\mathrm{it}}$ & Log \\
\hline 6 & $\mathrm{x}_{\mathrm{it}}=\Delta \ln \mathrm{z}_{\mathrm{it}} \times 100$ & Monthly Growth Rate \\
& $\mathrm{x}_{\mathrm{it}}=\Delta \ln \frac{\mathrm{z}_{\mathrm{it}}}{\mathrm{z}_{\mathrm{it}-12}} \times 100$ & Monthly difference of yearly growth rates \\
\hline
\end{tabular}

Table A2: Data Description

\begin{tabular}{|c|c|c|c|}
\hline Code & Description & Transf. & HP \\
\hline $\mathrm{a} 0 \mathrm{~m} 052$ & Personal income (AR, bil. chain $2000 \$$ ) & 5 & \\
\hline A0M051 & Personal income less transfer payments (AR, bil. chain 2000 \$) & 5 & \\
\hline IPS10 & INDUSTRIAL PRODUCTION INDEX - TOTAL INDEX & 5 & \\
\hline IPS11 & INDUSTRIAL PRODUCTION INDEX - PRODUCTS, TOTAL & 5 & \\
\hline IPS299 & INDUSTRIAL PRODUCTION INDEX - FINAL PRODUCTS & 5 & \\
\hline IPS12 & INDUSTRIAL PRODUCTION INDEX - CONSUMER GOODS & 5 & \\
\hline IPS13 & INDUSTRIAL PRODUCTION INDEX - DURABLE CONSUMER GOODS & 5 & \\
\hline IPS18 & INDUSTRIAL PRODUCTION INDEX - NONDURABLE CONSUMER GOODS & 5 & \\
\hline IPS25 & INDUSTRIAL PRODUCTION INDEX - BUSINESS EQUIPMENT & 5 & \\
\hline IPS32 & INDUSTRIAL PRODUCTION INDEX - MATERIALS & 5 & \\
\hline IPS34 & INDUSTRIAL PRODUCTION INDEX - DURABLE GOODS MATERIALS & 5 & \\
\hline IPS38 & INDUSTRIAL PRODUCTION INDEX - NONDURABLE GOODS MATERIALS & 5 & \\
\hline IPS43 & INDUSTRIAL PRODUCTION INDEX - MANUFACTURING (SIC) & 5 & \\
\hline IPS67e & INDUSTRIAL PRODUCTION INDEX - MINING NAICS=21 & 5 & \\
\hline IPS68e & INDUSTRIAL PRODUCTION INDEX - ELECTRIC AND GAS UTILITIES & 5 & \\
\hline IPS307 & INDUSTRIAL PRODUCTION INDEX - RESIDENTIAL UTILITIES & 5 & \\
\hline IPS316 & INDUSTRIAL PRODUCTION INDEX - BASIC METALS & 5 & \\
\hline PMP & NAPM PRODUCTION INDEX (PERCENT) & 1 & \\
\hline LHEL & INDEX OF HELP-WANTED ADVERTISING IN NEWSPAPERS (1967=100;SA) & 2 & \\
\hline LHELX & EMPLOYMENT: RATIO; HELP-WANTED ADS:NO. UNEMPLOYED CLF & 2 & \\
\hline LHEM & CIVILIAN LABOR FORCE: EMPLOYED, TOTAL (THOUS.,SA) & 5 & \\
\hline LHNAG & CIVILIAN LABOR FORCE: EMPLOYED, NONAGRIC.INDUSTRIES (THOUS.,SA) & 5 & \\
\hline LHUR & UNEMPLOYMENT RATE: ALL WORKERS, 16 YEARS \& OVER $(\%$, SA) & 2 & \\
\hline LHU680 & UNEMPLOY.BY DURATION: AVERAGE(MEAN)DURATION IN WEEKS (SA) & 2 & \\
\hline LHU5 & UNEMPLOY.BY DURATION: PERSONS UNEMPL.LESS THAN 5 WKS (THOUS.,SA) & 5 & \\
\hline LHU14 & UNEMPLOY.BY DURATION: PERSONS UNEMPL.5 TO 14 WKS (THOUS.,SA) & 5 & \\
\hline LHU15 & UNEMPLOY.BY DURATION: PERSONS UNEMPL.15 WKS + (THOUS.,SA) & 5 & \\
\hline LHU26 & UNEMPLOY.BY DURATION: PERSONS UNEMPL. 15 TO 26 WKS (THOUS.,SA) & 5 & \\
\hline $\begin{array}{l}\text { BLS_P- } \\
\text { service } \\
\text { EMP }\end{array}$ & Private Service-providing Employment - Seasonally Adjusted - CES0800000001 & 5 & \\
\hline $\begin{array}{l}\text { BLS_LPN } \\
\text { AG }\end{array}$ & Total Nonfarm Employment - Seasonally Adjusted - CES0000000001 & 5 & \\
\hline CES002 & EMPLOYEES ON NONFARM PAYROLLS - TOTAL PRIVATE & 5 & \\
\hline CES003 & EMPLOYEES ON NONFARM PAYROLLS - GOODS-PRODUCING & 5 & \\
\hline CES006 & EMPLOYEES ON NONFARM PAYROLLS - MINING & 5 & \\
\hline CES011 & EMPLOYEES ON NONFARM PAYROLLS - CONSTRUCTION & 5 & \\
\hline CES015 & EMPLOYEES ON NONFARM PAYROLLS - MANUFACTURING & 5 & \\
\hline CES017 & EMPLOYEES ON NONFARM PAYROLLS - DURABLE GOODS & 5 & \\
\hline CES033 & EMPLOYEES ON NONFARM PAYROLLS - NONDURABLE GOODS & 5 & \\
\hline
\end{tabular}




\begin{tabular}{|c|c|c|c|}
\hline CES046 & EMPLOYEES ON NONFARM PAYROLLS - SERVICE-PROVIDING & 5 & \\
\hline CES048 & $\begin{array}{l}\text { EMPLOYEES ON NONFARM PAYROLLS - TRADE, TRANSPORTATION, AND } \\
\text { UTILITIES }\end{array}$ & 5 & \\
\hline CES049 & EMPLOYEES ON NONFARM PAYROLLS - WHOLESALE TRADE & 5 & \\
\hline CES053 & EMPLOYEES ON NONFARM PAYROLLS - RETAIL TRADE & 5 & \\
\hline CES088 & EMPLOYEES ON NONFARM PAYROLLS - FINANCIAL ACTIVITIES & 5 & \\
\hline CES140 & EMPLOYEES ON NONFARM PAYROLLS - GOVERNMENT & 5 & \\
\hline CES151 & $\begin{array}{l}\text { AVERAGE WEEKLY HOURS OF PRODUCTION OR NONSUPERVISORY WORKERS } \\
\text { ON PRIVATE NONFAR }\end{array}$ & 1 & \\
\hline CES155 & $\begin{array}{l}\text { AVERAGE WEEKLY HOURS OF PRODUCTION OR NONSUPERVISORY WORKERS } \\
\text { ON PRIVATE NONFAR }\end{array}$ & 2 & \\
\hline $\begin{array}{l}\text { BLS_LEH } \\
\text { CC }\end{array}$ & $\begin{array}{l}\text { Construction Average Hourly Earnings of Production Workers - Seasonally Adjusted - } \\
\text { CES2000000006 }\end{array}$ & 5 & \\
\hline $\begin{array}{l}\text { BLS_LEH } \\
\text { M }\end{array}$ & $\begin{array}{l}\text { Manufacturing Average Hourly Earnings of Production Workers - Seasonally Adjusted - } \\
\text { CES3000000006 }\end{array}$ & 5 & \\
\hline PMEMP & NAPM EMPLOYMENT INDEX (PERCENT) & 1 & \\
\hline HSFR & $\begin{array}{l}\text { HOUSING } \\
\text { )(THOUS.,SA }\end{array}$ & 4 & \\
\hline HSNE & HOUSING STARTS:NORTHEAST (THOUS.U.)S.A. & 4 & I-II \\
\hline HSMW & HOUSING STARTS:MIDWEST(THOUS.U.)S.A. & 4 & \\
\hline HSSOU & HOUSING STARTS:SOUTH (THOUS.U.)S.A. & 4 & \\
\hline HSWST & HOUSING STARTS:WEST (THOUS.U.)S.A. & 4 & \\
\hline HSBR & HOUSING AUTHORIZED: TOTAL NEW PRIV HOUSING UNITS (THOUS.,SAAR) & 4 & I-II \\
\hline HMOB & MOBILE HOMES: MANUFACTURERS' SHIPMENTS (THOUS.OF UNITS,SAAR) & 4 & II \\
\hline RHPUS & Real U.S. House Price (SA) & 5 & \\
\hline PMI & PURCHASING MANAGERS' INDEX (SA) & 1 & \\
\hline PMNO & NAPM NEW ORDERS INDEX (PERCENT) & 1 & \\
\hline PMDEL & NAPM VENDOR DELIVERIES INDEX (PERCENT) & 1 & \\
\hline PMNV & NAPM INVENTORIES INDEX (PERCENT) & 1 & \\
\hline A0M008 & Mfrs' new orders, consumer goods and materials (bil. chain $1982 \$$ ) & 5 & \\
\hline A0M027 & Mfrs' new orders, nondefense capital goods (mil. chain 1982 \$) & 5 & \\
\hline FM1 & MONEY STOCK: M1(CURR,TRAV.CKS,DEM DEP,OTHER CK'ABLE DEP)(BIL\$,SA) & 6 & \\
\hline FM2 & $\begin{array}{l}\text { MONEY STOCK:M2(M1+O'NITE RPS,EURO\$,G/P\&B/D MMMFS\&SAV\&SM TIME } \\
\text { DEP(BIL\$, }\end{array}$ & 6 & \\
\hline FM3 & MONEY STOCK: M3(M2+LG TIME DEP,TERM RP'S\&INST ONLY MMMFS)(BIL\$,SA) & 6 & \\
\hline FM2DQ & MONEY SUPPLY - M2 IN 1996 DOLLARS (BCI) & 5 & \\
\hline FMFBA & MONETARY BASE, ADJ FOR RESERVE REQUIREMENT CHANGES(MIL\$,SA) & 6 & \\
\hline FMRRA & DEPOSITORY INST RESERVES:TOTAL,ADJ FOR RESERVE REQ CHGS(MIL\$,SA) & 6 & \\
\hline FMRNBA & DEPOSITORY INST RESERVES:NONBORROWED,ADJ RES REQ CHGS(MIL\$,SA) & 6 & \\
\hline FCLNQ & COMMERCIAL \& INDUSTRIAL LOANS OUSTANDING IN 1996 DOLLARS (BCI) & 6 & \\
\hline FCLBMC & WKLY RP LG COM'L BANKS:NET CHANGE COM'L \& INDUS LOANS(BIL\$,SAAR) & 1 & \\
\hline CCINRV & CONSUMER CREDIT OUTSTANDING - NONREVOLVING(G19) & 6 & \\
\hline FSPCOM & S\&P'S COMMON STOCK PRICE INDEX: COMPOSITE (1941-43=10) & 5 & \\
\hline FSPIN & S\&P'S COMMON STOCK PRICE INDEX: INDUSTRIALS (1941-43=10) & 5 & \\
\hline FSDXP & S\&P'S COMPOSITE COMMON STOCK: DIVIDEND YIELD (\% PER ANNUM) & 2 & \\
\hline FSPXE & S\&P'S COMPOSITE COMMON STOCK: PRICE-EARNINGS RATIO $(\%, N S A)$ & 5 & \\
\hline FSDJ & COMMON STOCK PRICES: DOW JONES INDUSTRIAL AVERAGE & 5 & \\
\hline PSCCOM & SPOT MARKET PRICE INDEX:BLS \& CRB: ALL COMMODITIES(1967=100) & 5 & \\
\hline FYFF & INTEREST RATE: FEDERAL FUNDS (EFFECTIVE) (\% PER ANNUM,NSA) & 2 & \\
\hline FYGM3 & INTEREST RATE: U.S.TREASURY BILLS,SEC MKT,3-MO.(\% PER ANN,NSA) & 2 & \\
\hline FYGM6 & INTEREST RATE: U.S.TREASURY BILLS,SEC MKT,6-MO.(\% PER ANN,NSA) & 2 & \\
\hline FYGT1 & INTEREST RATE: U.S.TREASURY CONST MATURITIES,1-YR.(\% PER ANN,NSA) & 2 & \\
\hline FYGT5 & INTEREST RATE: U.S.TREASURY CONST MATURITIES,5-YR.(\% PER ANN,NSA) & 2 & \\
\hline FYGT10 & INTEREST RATE: U.S.TREASURY CONST MATURITIES,10-YR.(\% PER ANN,NSA) & 2 & \\
\hline FYAAAC & BOND YIELD: MOODY'S AAA CORPORATE (\% PER ANNUM) & 2 & \\
\hline FYBAAC & BOND YIELD: MOODY'S BAA CORPORATE (\% PER ANNUM) & 2 & \\
\hline sfygm3 & fygm3-fyff & 1 & \\
\hline sFYGM6 & fygm6-fyff & 1 & \\
\hline
\end{tabular}




\begin{tabular}{|c|c|c|c|}
\hline sFYGT1 & fygt1-fyff & 1 & \\
\hline sFYGT5 & fygt5-fyff & 1 & \\
\hline sFYGT10 & fygt10-fyff & 1 & $\mathbf{I}$ \\
\hline $\begin{array}{l}\text { sFYAAA } \\
\text { C }\end{array}$ & fyaaac-fyff & 1 & \\
\hline $\begin{array}{l}\text { sFYBAA } \\
\text { C }\end{array}$ & fybaac-fyff & 1 & \\
\hline EXRSW & FOREIGN EXCHANGE RATE: SWITZERLAND (SWISS FRANC PER U.S.\$) & 5 & \\
\hline EXRJAN & FOREIGN EXCHANGE RATE: JAPAN (YEN PER U.S.\$) & 5 & \\
\hline EXRUK & FOREIGN EXCHANGE RATE: UNITED KINGDOM (CENTS PER POUND) & 5 & \\
\hline EXRCAN & FOREIGN EXCHANGE RATE: CANADA (CANADIAN \$ PER U.S.\$) & 5 & \\
\hline PWFSA & PRODUCER PRICE INDEX: FINISHED GOODS $(82=100$, SA $)$ & 6 & \\
\hline PWFCSA & PRODUCER PRICE INDEX:FINISHED CONSUMER GOODS $(82=100$, SA $)$ & 6 & \\
\hline PWIMSA & PRODUCER PRICE INDEX:INTERMED MAT.SUPPLIES \& COMPONENTS(82=100,SA) & 6 & \\
\hline PWCMSA & PRODUCER PRICE INDEX:CRUDE MATERIALS $(82=100$, SA) & 6 & \\
\hline PMCP & NAPM COMMODITY PRICES INDEX (PERCENT) & 1 & \\
\hline PUNEW & CPI-U: ALL ITEMS (82-84=100,SA) & 6 & \\
\hline PU83 & CPI-U: APPAREL \& UPKEEP $(82-84=100$, SA $)$ & 6 & \\
\hline PU84 & CPI-U: TRANSPORTATION $(82-84=100, \mathrm{SA})$ & 6 & \\
\hline PU85 & CPI-U: MEDICAL CARE (82-84=100,SA) & 6 & \\
\hline PUC & CPI-U: COMMODITIES (82-84=100,SA) & 6 & \\
\hline PUCD & CPI-U: DURABLES $(82-84=100$, SA) & 6 & \\
\hline PUXF & CPI-U: ALL ITEMS LESS FOOD $(82-84=100$, SA $)$ & 6 & \\
\hline PUXHS & CPI-U: ALL ITEMS LESS SHELTER $(82-84=100$, SA) & 6 & \\
\hline PUXM & CPI-U: ALL ITEMS LESS MIDICAL CARE $(82-84=100$, SA) & 6 & \\
\hline HHSNTN & U. OF MICH. INDEX OF CONSUMER EXPECTATIONS(BCD-83) & 2 & \\
\hline
\end{tabular}

Note: I and II indicate the variables selected at the beginning of 2001:01 and/or at the end of 2004:10, respectively, by the Lasso regression. 